\title{
Mutual Determination of Trifluoperazine Hydrochloride and Vanadium (V) Ions in Real Matrices by Visible Spectrophotometry After Cloud Point Extraction
}

\author{
Zuhair A-A. Khammas ", Rana Abbas Rashid \\ Department of Chemistry, College of Science for Women, University of Baghdad, Jadiyriah, Baghdad, Iraq
}

Email address:

saifkhammas@gmail.com (Z. A-A. Khammas), rana.abbas.1982@gmail.com (R. A. Rashid)

To cite this article:

Zuhair A-A. Khammas, Rana Abbas Rashid. Mutual Determination of Trifluoperazine Hydrochloride and Vanadium (V) Ions in Real Matrices by Visible Spectrophotometry After Cloud Point Extraction. Science Journal of Analytical Chemistry. Vol. 3, No. 5, 2015 , pp. 61-70. doi: 10.11648/j.sjac.20150305.14

\begin{abstract}
A green method was established for the mutual determination of the drug trifluoperazine hydrochloride (TFPH) and vanadium (V) in real samples by coupling the cloud point extraction with UV-Vis spectrophotometry. The method was based on the formation of the colored V (V)-TFPH complex in acidic medium followed the extraction of the complex by using the surfactant Triton X-114 as an extracting medium. The surfactant-rich phase extracted was dissolved in a small volume of solvent and both the drug TFPH and V (V) ions determined by spectrophotometry at maximum absorption wavelength of $476 \mathrm{~nm}$. Most parameters which impact on the extraction efficiency and detection for both target analytes were optimized. Under the optimum conditions established, the preconcentration factor was found to be of 50 fold making Beer's law obeyed in the concentration range of 2-80 $\mu \mathrm{g} \mathrm{mL}^{-1}(\mathrm{r}=0.9999)$ for the determination of TFPH and $0.5-10 \mu \mathrm{gL}^{-1}(\mathrm{r}=0.9995)$ for vanadium $(\mathrm{V})$, giving the detection limits of 1.21 and $0.113 \mu \mathrm{g} \mathrm{mL}^{-1}$ respectively. The mean recovery percentage of $98.94 \pm 2.19 \%$ (in blood serum) and $99.43 \pm 1.40$ (in tap water); the precision (RSD \%) ranged between 0.48-3.40 \% and 0.45-1.49 were obtained for TFPH and V (V) ions respectively. The proposed method was employed for the determination of TFPH in pharmaceuticals and the spiked serum samples, while a $\mathrm{V}(\mathrm{V})$ ion was determined in black pepper samples.
\end{abstract}

Keywords: Trifluoperazine Hydrochloride, Vanadium (V) Ions, Hydrophobic Complex, Cloud Point Extraction, Vis - Spectrophotometry

\section{Introduction}

The exploitation of cloud point extraction methodology for the determination of two target analytes mutually in the same reaction system may really become an attractive avenue after the success that achieved in our recently published work [1]. In fact, that work reflects the importance of this trend, which we believe it will add some benefits and analytical features to the contemporary analytical chemistry by simplifying the analytical procedures in the terms of economy in time and expenses, as well as reducing the analytical chemist efforts. This is what encouraged us to continue to offer other works in this direction for the purpose of devising other new methods before us. In current work, the reaction between the vanadium (V) ions with drug trifluopearazine hydrochloride (TFPH) in acidic medium was adopted as a complexometric reaction system to form a soluble colored V (V)-TFPH complex. The main reason for selection of this reaction because the drug
TFPH and V (V) have a great importance to humans.

Trifluoperazine hydrochloride (TFPH) is one of the very important class of phenothaizine derivatives, where it mainly used as a treatment for Schizophrenia in addition to other psychotic disorders [2]. It chemically known as 10 - [3 - (4methylpiperazin - 1 - yl) propyl] - 2 - (trifluoromethyl) $10 H$ - phenothiazine hydrochloride as showed in Figure 1.

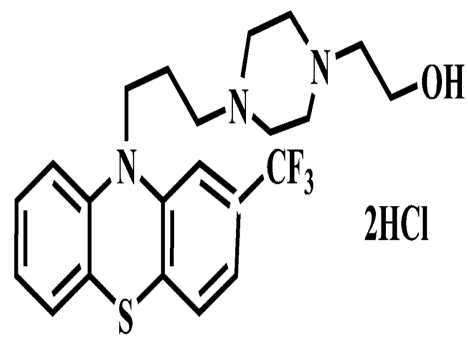

Figure 1. The chemical structure of Trifluoperazine hydrochloride $\left(\mathrm{C}_{21} \mathrm{H}_{24} \mathrm{~F}_{3} \mathrm{~N}_{3} \mathrm{~S} . \mathrm{HCl}, \mathrm{M} . \mathrm{W} .480 .43 \mathrm{~g} / \mathrm{mol}\right)$ [3]. 
TFFH is subjected to many research works, either for the development of the methods of its determination in pure form and pharmaceuticals or as chromogenic reagent for estimation of various target analytes. The literature survey reveals that a number of analytical methods for detection of this drug individually or in combination with other drugs have been used including, indirect atomic absorption spectrometry [4], potentiometry [5], reverse phase high performance liquid chromatography (RP-HPLC) [6-13], solid-phase extraction-high performance liquid chromatography (SPE-HPLC) [14], liquid chromatography - mass spectrometry / mass spectrometry (LC-MS/MS) [15] densitometry [16] and spectrophotometry [17-20]. Also, this drug was proposed as a chelating agent for the determination of some metal ions like $\mathrm{Cr}^{+6}[21], \mathrm{Tl}^{3+}$ [22], $\mathrm{Fe}^{3+}$ [23] ions. In general, one can refer to the analytical applications of the reactions of phenothiazine derivatives with some metal ions through access to the best article published an article in 1999 [24].

Vanadium, on the other hand, is an essential element for cell growth at trace amount $\left(\mu \mathrm{g} \mathrm{L}^{-1}\right)$ level and playing an important role in the regulation of enzymes, but it can be toxic at higher concentration of humans and animals [25]. However, the toxicity of vanadium is dependent on its oxidation state, with vanadium (V) being more toxic than vanadium (IV) and its poisoning symptoms are sometimes fatal [26]. Therefore, the determination of vanadium is so important especially in foods and environmental samples. Among the most instrumental methods reported for the determination of vanadium include electrothermal atomic absorption spectrometry (ETAAS) [27-28], neutron activation analysis (NAA)[29-30] inductively coupled plasma mass spectrometry (ICP-MS) [31-32] inductively coupled plasma optical emission spectrometry (ICP-OES) [33-36] and voltammetry [37].

From the above, it is evident that some of these techniques, whether for TFPH or vanadium determination have some disadvantages in term of non-selectively, expensive instrumentations, time-consuming, unavailable in many laboratories. Because of these two target analytes under study exists at trace concentration level and in complex matrices, the direct determination is very difficult and the separation and pre-concentration of these are a must before their determination. Accordingly, the hyphenation of cloud point extraction(CPE) with UV-Vis spectrophotometry offers fascinating features that pay towards simplification of the analytical procedures in routine analyzes of organic compounds and metal ions in various matrices rather than using sophisticated and expensive instrumentation [1, 38].

The current work is an extension of our previous attempts to entrench the concept of mutual analysis of the two target analytes at the same time by using CPE coupled with molecular spectrophotometry. The method based on the complexation reaction between vanadium(V) and the drug TFPH in acidic medium to form V(V)-TFPH complex which extracted into an non-ionic surfactant (Triton X-114) followed by their determination spectrophotometrically at specific absorption maximum, in biological, food and environmental samples.

\section{Materials and Methods}

\subsection{Apparatus}

All absorption measurements of the two target analytes and the scanning of the absorption spectra for the complex under study were carried by using a Shimadzu double-beam UV-Vis Spectrophotometer model UV-1800 (Kyoto, Japan) equipped with 5-mm optical path cell. A double-beam atomic absorption spectrometer AA400 (Analytic Jeana, Germany) equipped with a graphite furnace was used for the determination of vanadium according to the instruction manual of the company. Thermostatic water bath model WNB7-45 Experts (England) was employed for CPE experiments. For solution $\mathrm{pH}$ measurements, a portable $\mathrm{pH} / \mathrm{mV} / \mathrm{C}$ meter HI 83141 (HANNA, Romania) was used.

\subsection{Reagents and Materials}

The materials and reagents used in this work with high purity, doubly distilled water was used in the preparation of all solutions and for final rinsing of glass wares. Triton X-114 (purity $>99.9 \%$ ), was purchased from AMRESCO LLC (Solon, USA). A $10 \%(\mathrm{v} / \mathrm{v})$ of Triton X-114 was prepared by diluting $10 \mathrm{~mL}$ in $100 \mathrm{~mL}$ water. A pure grade $(99 \%)$ of trifluoperazin hydrochloride was obtained from the Directorate General of Drug Supervision / Baghdad-Iraq. A stock solution of $1000 \mu \mathrm{g}$ $\mathrm{mL}^{-1}$ (or $0.002 \mathrm{M}$ ) for the drug Trifluoperazin was prepared by dissolving $0.1000 \mathrm{~g}$ in a minimum amount of water and dilutes to mark with doubly distilled water in a $100 \mathrm{~mL}$ volumetric flask. This solution was stored in the refrigerator and working solutions were daily prepared by appropriate dilutions in water. A stock solution of $1000 \mathrm{mg} \mathrm{L}^{-1}$ (or $0.02 \mathrm{M}$ ) for $\mathrm{V}(\mathrm{V}$ ) was prepared by dissolving $0.2296 \mathrm{~g}$ of pre-dried ammonium metavandate $\left(\mathrm{NH}_{4} \mathrm{VO}_{3}, \mathrm{M}\right.$. wt $\left.116.978 \mathrm{~g} \mathrm{~mol}^{-1}, \mathrm{BDH}\right)$ in $5 \mathrm{~mL}$ doubly distilled water and complete to mark with water in 100 $\mathrm{mL}$ volumetric flask.0.1 $\mathrm{M}$ hydrochloric acid solution was prepared by diluted $0.83 \mathrm{~mL}$ of $37 \% \mathrm{HCl}(1.19 \mathrm{~g} / \mathrm{mL}, \mathrm{BDH})$ with distilled water in $100 \mathrm{~mL}$ calibrated flask.

\subsection{General Procedure for CPE for TFPH}

In a series of $10 \mathrm{~mL}$ volumetric flasks, an amount of TFPH standard or sample solution matched within the calibration range $\left(2-80 \mu \mathrm{g} \mathrm{mL}^{-1}\right)$, an excess of $4 \times 10^{-4} \mathrm{M}$ (or $20 \mu \mathrm{g} \mathrm{mL}^{-1}$ ) vanadium ion solution, $\mathrm{pH}$ adjusted to 1.5 with $\mathrm{HCl}$ and 0.2 $\mathrm{mL}$ of Triton X-114 (10\% v/v) were added, mixed and dilute with to mark with water. The content of each flask was transferred into a $10 \mathrm{~mL}$ centrifuging tube and all kept in the thermostatic bath at $75{ }^{\circ} \mathrm{C}$ for $30 \mathrm{~min}$ for clouding. The separation of the surfactant-rich phase was performed by centrifugation at $6000 \mathrm{rpm}$ for $20 \mathrm{~min}$ and thereafter cooled down in an ice bath to increase the viscosity of cloud point layer. The aqueous phase was easily poured by inverting the tube. The surfactant-rich phase that contains the complex was dissolved with $1 \mathrm{~mL}$ ethanol and the absorbance of the complex measured at $476 \mathrm{~nm}$ against a reagent blank prepared under similar conditions. The residual TPPH in aqueous solution was determined by traditional 
spectrophotometry at $\lambda_{\max }$ of $307 \mathrm{~nm}$ in order to determine the distribution ratio (D) and extraction efficiency $(\% \mathrm{E})$.

\subsection{General Procedure for CPE for V(V) Ion}

In series of $10 \mathrm{~mL}$ volumetric flasks containing known amount vanadium (V) standard or sample solution matched within the calibration range $\left(0.5-10 \mu \mathrm{g} \mathrm{mL} L^{-1}\right)$, an excess of $1.2 \times 10^{-4} \mathrm{~mol} \mathrm{~L}^{-1}$ TFPH reagent solution, $\mathrm{pH}$ adjusted to 1.5 with $\mathrm{HCl}$ and $0.2 \mathrm{~mL}$ of Triton $\mathrm{X}-114(10 \%)$ were mixed and diluted to mark with distilled water, then followed the same general CPE for TFPH. The vanadium content was measured at $\lambda_{\max }$ of $476 \mathrm{~nm}$.

\subsection{Preparation of Stelazine Tablet}

Ten tablets of Stelazine were crushed to a powder in a clean agate mortar and triturated well. A quantity of fine powder $(0.3770 \mathrm{~g})$ was dissolved in a sufficient volume of water with continuous shaking, and then filtered. The filtrate was transferred into a $100 \mathrm{~mL}$ volumetric flask and diluted to the mark with water. Aliquots of Stelazine sample solution were pipetted into seven $10 \mathrm{~mL}$ calibrated flasks containing $0.5,1.0$ and $2.0 \mathrm{~mL}$ of $50 \mu \mathrm{g} \mathrm{mL}^{-1} \mathrm{TFPH}$ and each solution followed general CPE procedure for TFPH and the content of drug was measured spectrohotometrically at $\lambda_{\max }$ of $476 \mathrm{~nm}$.

\subsection{Preparation of Blood Serum Sample}

Blood sample was selected from one volunteer via withdrawing $5 \mathrm{~mL}$ from the vein using medical syringe. The sample was transferred immediately into centrifuging tube and the content centrifuged for $15 \mathrm{~min}$ to remove the serum from the whole blood, then kept freezing in a refrigerator until analysis. The serum sample was thawed at ambient temperature, $0.2 \mathrm{~mL}$ of serum sample was spiked with 0.2 , 0.3 and $0.4 \mathrm{~mL}$ of $1000 \mu \mathrm{g} \mathrm{mL}{ }^{-1}$ TFPH into a $10 \mathrm{~mL}$ volumetric flasks and followed general CPE procedure for TFPH. The content in the complex determined spectrophotometrically at $\lambda_{\max } 476 \mathrm{~nm}$.

\subsection{Preparation of Water Samples}

About one liter of drinking and river water samples were collected from the campus of University of Baghdad and river water was first filtered off to remove any suspended materials. A $5 \mathrm{~mL}$ of each sample was transferred into $10 \mathrm{~mL}$ volumetric flask and spiked with $0.1,0.3$ and $0.5 \mathrm{~mL}$ of $1000 \mu \mathrm{g} \mathrm{mL}$ $\mathrm{TFPH}$, then followed the general CPE procedure for TFPH. The content of TFPH in the complex determined spectrophotometrically at $\lambda_{\max } 476 \mathrm{~nm}$. Also, $5 \mathrm{~mL}$ of each sample was transferred into $10 \mathrm{~mL}$ volumetric flask and spiked with $0.2,0.4$ and $0.6 \mathrm{~mL}$ of $100 \mu \mathrm{g} \mathrm{mL}^{-1} \mathrm{~V}(\mathrm{~V})$ ion, then followed the general CPE procedure for $\mathrm{V}(\mathrm{V})$. The content $\mathrm{V}(\mathrm{V})$ ions in the complex was determined spectrophotometrically at $\lambda_{\max } 476 \mathrm{~nm}$.

\subsection{Preparation of Black Pepper Samples}

The dry ashing method was adopted for preparation of pepper sample solutions, by taking approximately $5 \mathrm{~g}$ of black pepper separately into a porcelain crucible and heated on hotplate under gentle heating till smoke ceased, then the content transferred into a muffle furnace at $450-550{ }^{\circ} \mathrm{C}$ until white ash. The content of each sample was dissolved in $2 \mathrm{~mL}$ concentrated $\mathrm{HCl}$ and heated on hotplate till dry. Further $2 \mathrm{~mL}$ of $4 \mathrm{M} \mathrm{HCl}$ was added and repeated twice until clear solution. The solution was transferred into $5 \mathrm{~mL}$ volumetric flask and completed to mark with water. Each sample solution was subjected to the general CPE procedure for vanadium ion determination.

\subsection{Statistical Analysis}

Excel 2007 (Microsoft Office $^{\circledR}$ ) and Minitab version 14 (Minitab Inc., State College, PA, USA) were employed to carry out all statistical calculations such as regression and correlation analysis, ANOVA and significance tests.

\section{Results and Discussion}

\subsection{Absorption Spectra}

In a series of preliminary attempts to ensure the formation of the complex between V (V) and TFPH at concentration of $1 \times 10^{-4} \mathrm{M}$ in a strong acidic medium, an orange-purple water soluble complex was formed with a maximum absorption at $476 \mathrm{~nm}$ when measured against reagent blank which has negligible absorption at this wavelength. Thereafter, the absorption spectrum of the V (V)-TFPH complex between 190-900 nm was recorded after obtaining the optimal conditions listed below by applying the general CPE procedure. It was observed that there is an absorption band occurred at the same wavelength (i.e. $476 \mathrm{~nm}$ ) with a remarkable shoulder, indicating the formation of a complex between $\mathrm{V}(\mathrm{V})$ ions and TFPH drug as shown in Figure 2c. Whilst pure TFPH solution have two absorption maxima at 257 and $308 \mathrm{~nm}$ (Figure 2b) and the $\mathrm{V}(\mathrm{V})$ ion displays one distinct band at $233 \mathrm{~nm}$ (Figure 2a). Therefore, the wavelength maximum of $476 \mathrm{~nm}$ for $\mathrm{V}(\mathrm{V})$-TFPH complex was adopted throughout this study.

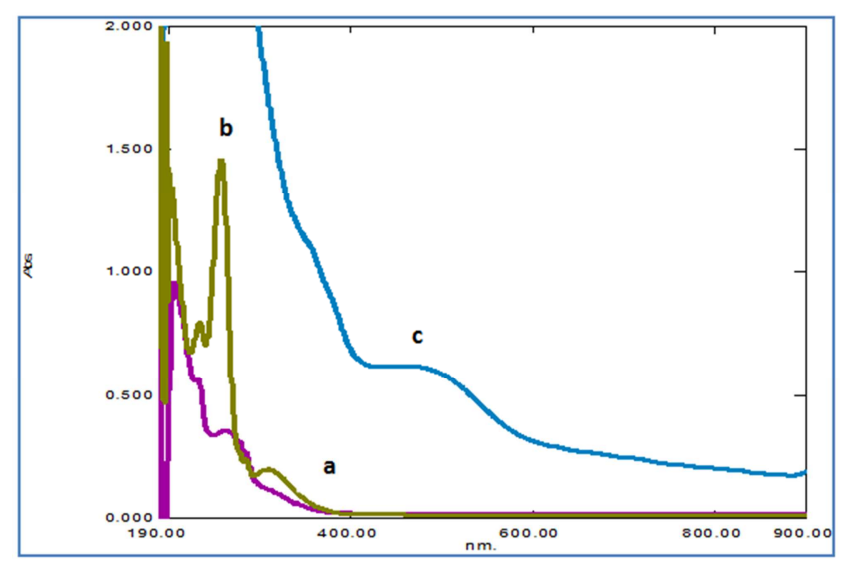

Figure 2. Absorption spectra Absorption spectra (a) V(V) solution (b) TFPH solution and (c) V(V)-TFPH complex in surfactant rich-phase. 


\subsection{Optimization of Experimental Conditions}

The effect of various important factors that impact the efficiency of the cloud point extraction procedure was carried via a follow-up series of experiments using classical optimization which suggests observing the effect of one factor at a time (OFAT) on the instrumental response while other factors are maintained at constant level. Thus, a satisfactory sensitivity of the measurement can be achieved. In this regard, the factors such as, $\mathrm{HCl}$ concentration, $\mathrm{V}(\mathrm{V})$ concentration, Triton X-114 amount, and equilibration temperature and incubation time were studied.

\subsubsection{Effect of $p H$}

The complexation reaction between $\mathrm{V}(\mathrm{V})$ and TFPH drug was formed in acidic medium. This condition is not just responsible for the stoichiometry of the complex, but has also an important effect in the thermodynamic equilibrium for the formation and stability of the complex extracted by CPE. Consequently, the effect of $\mathrm{pH}$ on the formation $\mathrm{V}(\mathrm{V})-\mathrm{TFPH}$ complex in Triton X-114 medium was studied by measuring the absorbance at $\lambda_{\max }$ of $476 \mathrm{~nm}$ over the range of 1-6. The experiments were conducted with $50 \mu \mathrm{g} \mathrm{mL}^{-1}$ drug TFPH, $5 \times 10^{-4} \mathrm{M}$ V(V) and $0.5 \mathrm{mLof}(10 \% \mathrm{v} / \mathrm{v})$ Triton $\mathrm{X}-114$ followed the CPE procedure, as shown in Figure 3. It was noticed that the absorbance suddenly increased and reached a maximum at $\mathrm{pH}=1.5$. Later, it decreases at high $\mathrm{pH}$ due to the dissociation of the complex and in incomplete extraction in micelle due to the shifting in the formation reaction toward left. Therefore, a $\mathrm{pH}$ of 1.5 was chosen for subsequent experiments.

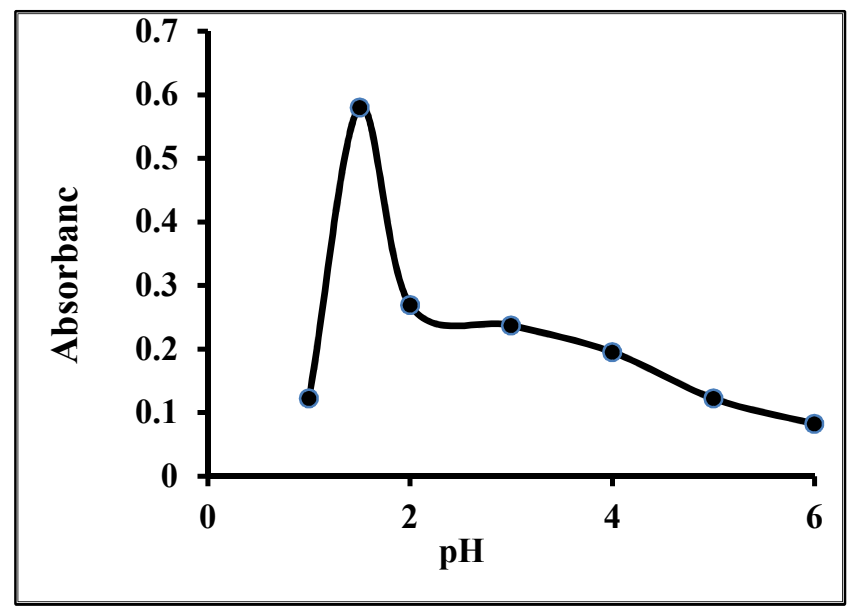

Figure 3. Effect of $p H$ on the formation of $V(V)-T F P H$ complex.

\subsubsection{Effect of $V(V)$ Ions Concentration}

The influence of $\mathrm{V}(\mathrm{V})$ concentration plays a major role in the formation of the V(V)-TFPH complex in acidic medium and its stability after CPE process. These experiment were carried out by measuring the absorbance of the solutions containing $50 \mu \mathrm{g} \mathrm{mL}^{-1} \mathrm{TFPH}$, varying concentration of the $\mathrm{V}(\mathrm{V})$ solution ranged from $1 \times 10^{-4}-8 \times 10^{-4} \mathrm{M}$ at $\mathrm{pH} 1.5$ and $0.5 \mathrm{~mL}$ of $(10 \% \mathrm{v} / \mathrm{v})$ of Triton X-114 at temperature $75^{\circ} \mathrm{C}$ for 30 min. The results are displayed in Figure 4. It was shown that the concentration of $\mathrm{V}(\mathrm{V})$ ions at $4 \times 10^{-4} \mathrm{M}$ was enough to obtain the maximum absorbance and it was used in the subsequent experiments. At higher $\mathrm{V}(\mathrm{V})$ ions concentration, a decrease in the absorbance of the complex was obvious due the deviation of the equilibrium toward the backward reaction because of law of mass action. Whilst at lower concentration of $\mathrm{V}(\mathrm{V})$ ions, no there any way for complex formation completion which leads to less amount of the drug complex extracted into the cloud point layer. Thus, $4 \times 10^{-4} \mathrm{M}$ of $\mathrm{V}(\mathrm{V})$ ion concentration was as optimum throughout this study.

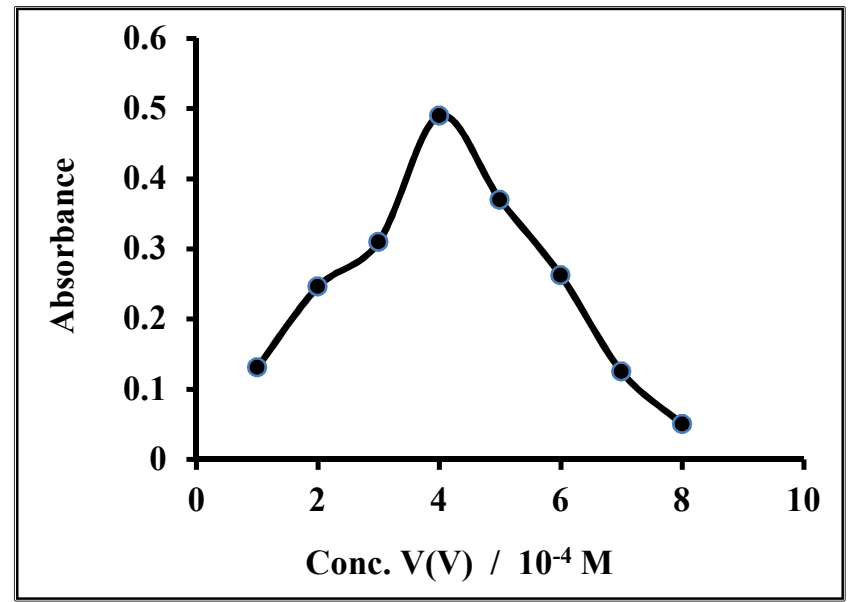

Figure 4. Effect of $V(V)$ concentration in the formation $V(V)$ - TFPH complex by $C P E$.

\subsubsection{Effect of Surfactant Amount}

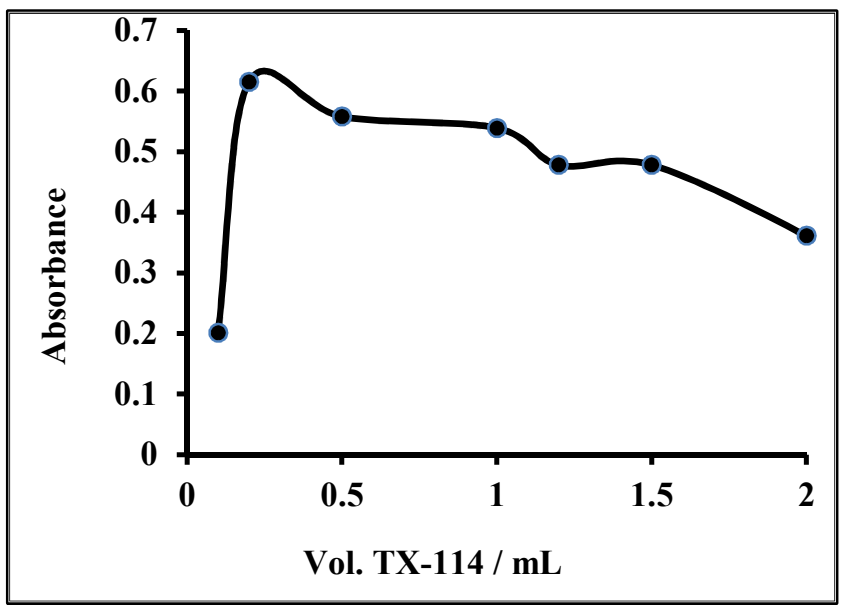

Figure 5. Effect of Triton X-114 amount on the absorbance of $V(V)-T F P H$ complex.

The amount of a non-ionic surfactant has a great significant for maximizing extraction efficiency by minimizing the phase volume ratio $\left(\mathrm{V}_{\mathrm{s}} / \mathrm{V}_{\mathrm{a}}\right)$, thus improving its perconcentration ability [39]. Figure 5 displays the effect of the Triton X-114 amount on the absorbance of the extracted $\mathrm{V}(\mathrm{V})$-TFP complex within the surfactant volume range of $0.1-2 \mathrm{~mL}$ of $10 \%(\mathrm{v} / \mathrm{v})$ Triton X-114 at constant other parameters. It was appeared that the absorbance the $\mathrm{V}(\mathrm{V})$-TFPH complex increases rapidly with increasing the Triton X-114 amount up to $0.2 \mathrm{~mL}$ of $10 \%(\mathrm{v} / \mathrm{v})$ and then 
markedly decreased at higher amounts. For low amount of Triton X-114, low sensitivity or extraction efficiency occurs owing to the inadequacy of the assemblies to entrap the hydrophobic complex quantitatively. While at higher amount led to deteriorating the detection signal and thus inefficient extraction. Therefore, a volume of $0.2 \mathrm{~mL}$ of $10 \%$ Triton $\mathrm{X}-114$ was found to be enough to obtain the point cloud layer with the smaller volume and higher viscosity and was used as the optimum amount.

\subsubsection{Effect of Temperature and Time}

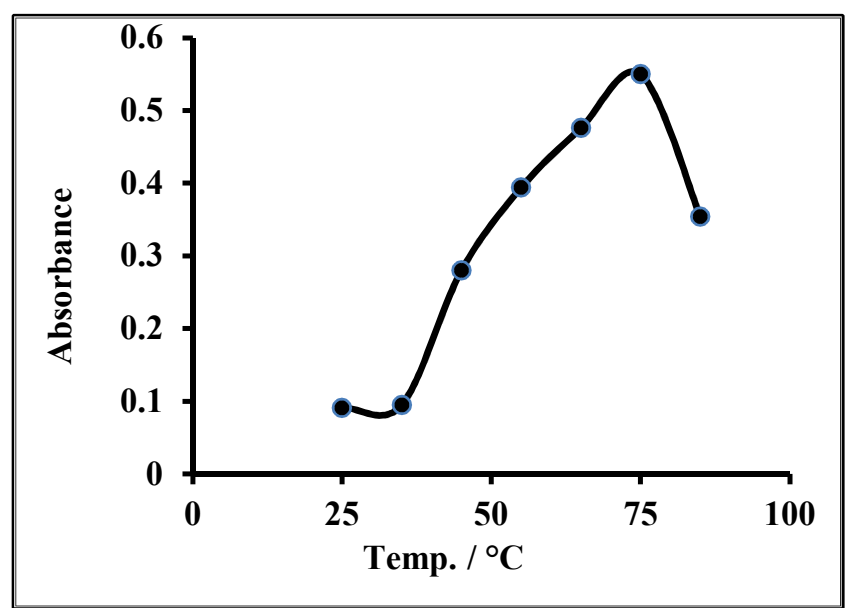

Figure 6. Effect of equilibration temperature on the CPE of $V(V)-T F P H$ complex.

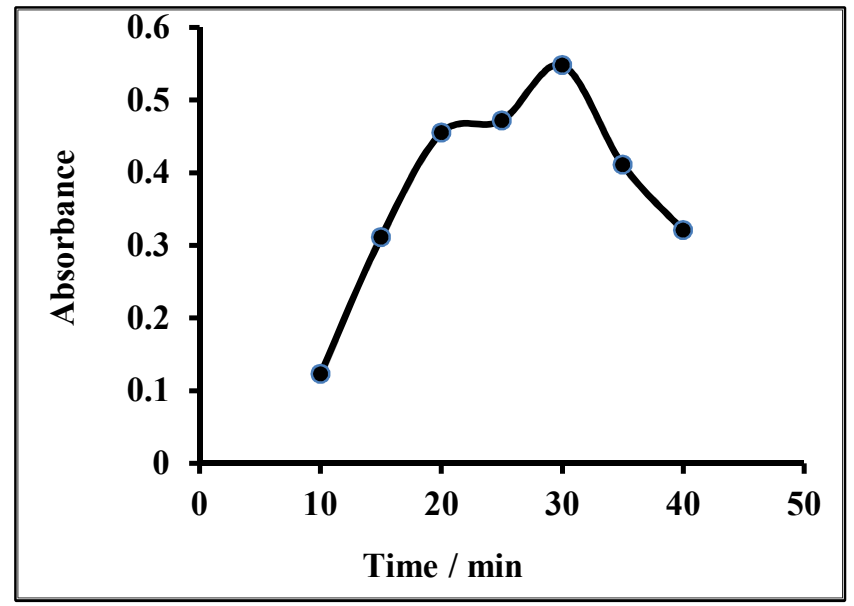

Figure 7. Effect of incubation time on the CPE of $V(V)$ - TFPH complex.

Figure 6 shows the impact of equibilibration temperature on the extraction of $\mathrm{V}(\mathrm{V})$ - TFPH complex by varying the temperature from 25 to $85{ }^{\circ} \mathrm{C}$ at incubation time of $30 \mathrm{~min}$ and keeping other variables constant. It was observed that the formation of cloud point layer (i.e. agglomeration of surfactant micelles) was achieved at $75{ }^{\circ} \mathrm{C}$, giving the maximum absorbance for $\mathrm{V}(\mathrm{V})$ - TFP complex and decreased thereafter. Thus, an equilibration temperature of 75 was selected as optimal. Figure 7 represents the influence of the incubation time from 10 to $40 \mathrm{~min}$ at previously optimized parameters in order to attain the equilibrium between two phases (i.e. surfactant-rich and bulk aqueous phases) via the gathering the surfactant micelles[1]. It was noticed that the incubation time of $30 \mathrm{~min}$ was sufficient for the maximum absorbance of $\mathrm{V}(\mathrm{V})$ - TFPH complex. The effect of centrifugation rate and time was also considered and found that a centrifugal time of $20 \mathrm{~min}$ at $3500 \mathrm{rpm}$ was sufficient to easy separate the two phase.

\subsection{Optimization Parameters for V(V) Using TFPH Drug}

The constant parameters as with TFPH drug determination were optimized, but a discrete variable here is the concentration of TFPH as chelating agent. At constant and trace concentration of $\mathrm{V}(\mathrm{V})$ of $5 \mu \mathrm{g} \mathrm{mL} \mathrm{m}^{-1}$, the optimum conditions of most parameters were similar to that obtained in the case TFPH optimization, but here it needs $1.2 \times 10^{-4} \mathrm{M}$ concentration of TFPH as optimal for the formation of V (V)TFPH complex as shown in Figure 8.

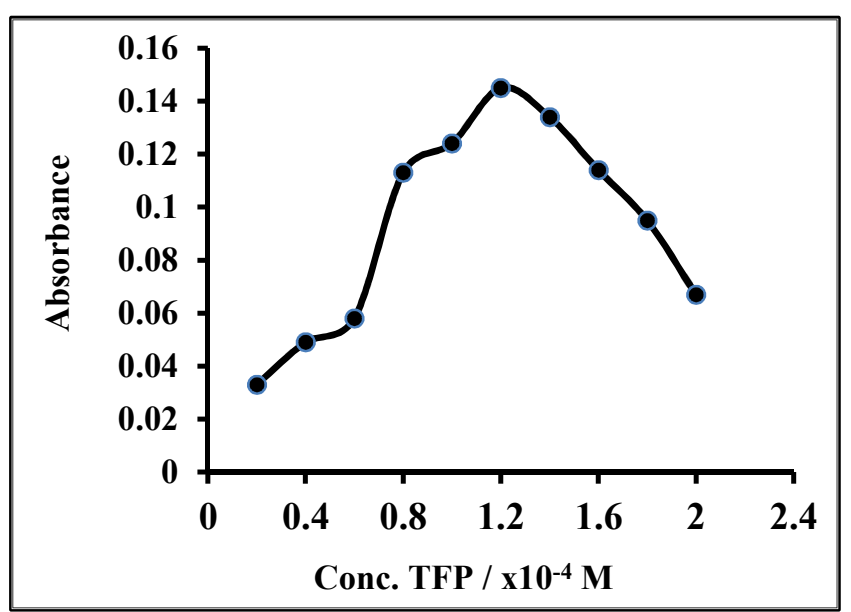

Figure 8. Effect of TFPH concentration for the formation of $V(V)-T F P H$ complex by CPE.

\subsection{Stoichiometry of the V(V)-TFPH Complex}

In a preliminary study, it was observed that an orange-purple color is instantly formed when $\mathrm{V}(\mathrm{V})$ ion solution is added to a certain amount of TFPH drug in the presence of a wide concentration of $\mathrm{HCl}$, indicative the complex formation. But, in this study the optimum $\mathrm{pH}$ of 1.5 was found to be enough for the stable colored complex formation which appeared in visible region with maximum absorbance at $476 \mathrm{~nm}$. Consequently, mole ratio method was used to measure the stoichiometry of $\mathrm{V}$ : TFPH ratio at optimum acid medium. This method was conducted at constant amount of $\mathrm{V}(\mathrm{V})$ with varying amount of TFPH at optimum conditions as showed in Figure 9. Obviously, the plotted curve exhibits a maximum for a mole ratio of $\mathrm{V}(\mathrm{V})$-TFPH complex via the point of intersection of the two lines which equal to 0.95 , indicating that the expected ratio of V: TFPH in the complex was of about $1: 1$. The Job plot (continuous variation method) was also confirmed similar result to the former method which exhibited that the mole fraction close to 0.45 , indicating again that the ratio of V: drug in the complex is 1:1 as displayed in Figure 10.

The formation constant $\left(\mathrm{K}_{\mathrm{f}}\right)$ of the $\mathrm{V}(\mathrm{V})$-TFP complex can 
be determined assuming only a single complex is present by using the data of continuous variation calculated according to the procedure adopted elsewhere [40] found to be of 3 . $19 \times 10^{5} \mathrm{~L} \mathrm{~mol}^{-1}$ at $476 \mathrm{~nm}$. Depending on the above result it can be concluded that the most probable structure of the complex formed between $\mathrm{V}(\mathrm{V})$ and TFPH in dilute acidic medium as displayed in Figure 11.

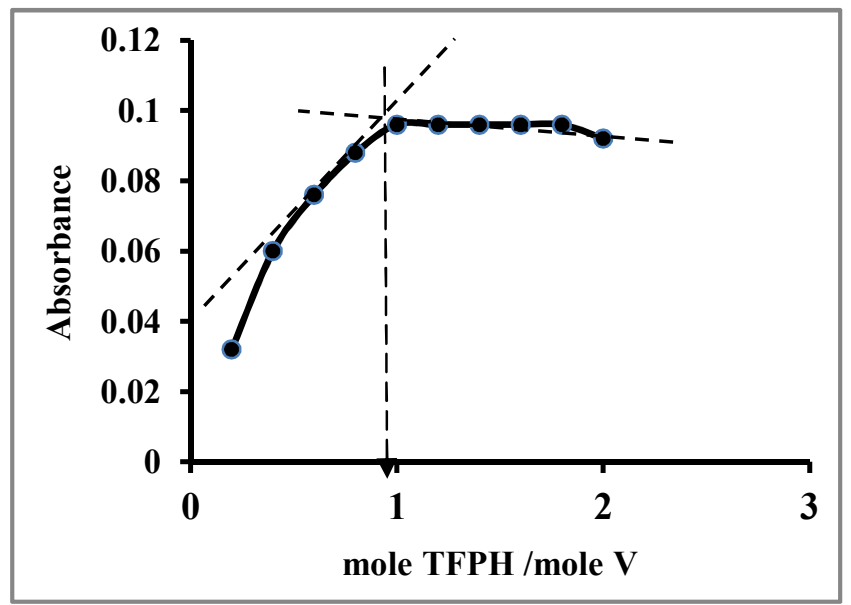

Figure 9. Mole ratio method for V(V)-TFPH complex.

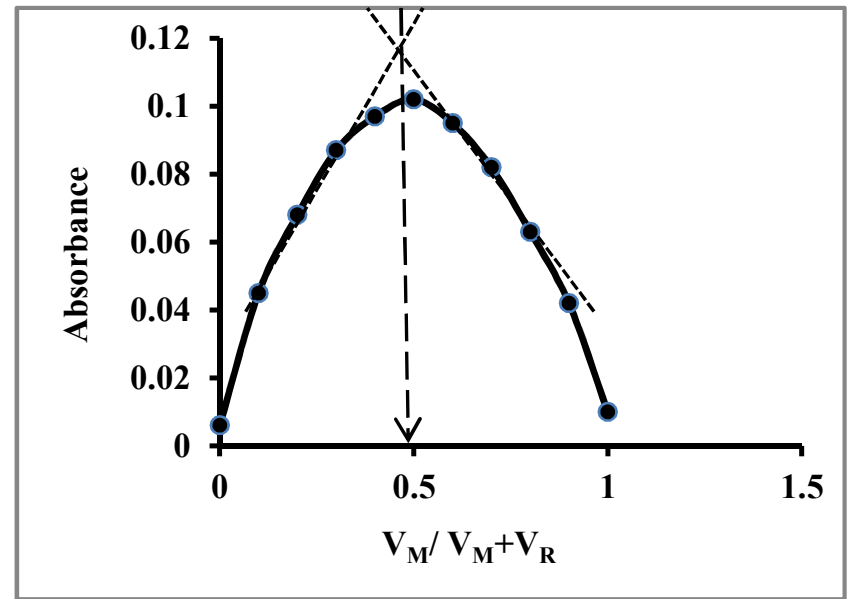

Figure 10. Continuous variation method for V(V)-TFPH complex.

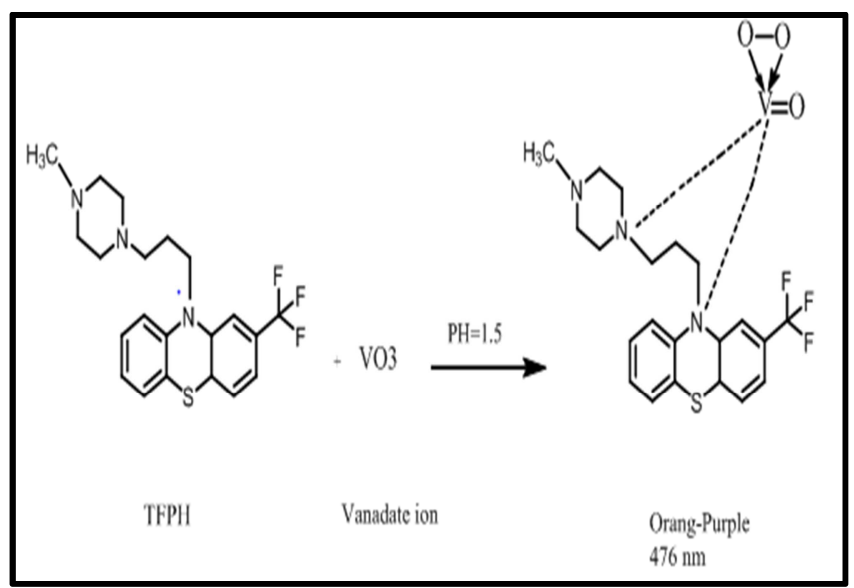

Figure 11. The probable structure of the complex formed between $V(V)$ and TFPH in acidic medium.

For the purpose of verification of complexation reaction between $\mathrm{V}(\mathrm{V})$ ions and TFPH drug from thermodynamic point of view, the standard free energy $\left(\Delta \mathrm{G}^{\circ}\right)$ can be calculated from the following relationship [41];

$$
\Delta G^{\circ}=-2.303 R T \log K
$$

where $\mathrm{R}$ is the gas constant $\left(1.987 \mathrm{cal} \mathrm{mol}^{-1}\right.$ degree $\left.^{-1}\right), \mathrm{T}$ is the optimum temperature in Kelvin $\left(348{ }^{\circ} \mathrm{K}\right)$, and $\mathrm{K}$ is the formation constant of V-TFPH complex $\left(\mathrm{L} \mathrm{mol}^{-1}\right)$. It found that the standard free energy $\left(\Delta \mathrm{G}^{\circ}\right)$ for the complexation reaction of between $\mathrm{V}(\mathrm{V})$ ions TFP drug was of a negative value and equal to $(-8.764) \mathrm{kcal} \mathrm{mol}^{-1}$, indicating that the complexation reaction is a spontaneous.

\subsection{Calibration Curves for TFPH Drug and V(V) Ions}

Under the optimized conditions established by CPE procedure for the determination of TFPH using $\mathrm{V}(\mathrm{V})$ ions, and for determination of $\mathrm{V}(\mathrm{V})$ ion using TFPH were constructed. All figures of merit for target analytes such as linear range, correlation coefficient, molar absorptivity, Sandell's sensitivity, detection limit and quantification limit were calculated according to the statistical equations which were summarized in Table 1 and 2. The statistical evaluation for the two calibration curves reveals that that the linear regression equations $\quad[\mathrm{y}=(0.0111 \pm 0.00012) \mathrm{x}-(0.00068 \pm 0.0056)] \quad$ and $[\mathrm{y}=(0.0308 \pm 0.0032) \mathrm{x}+(0.0058 \pm 0.0018)$ for TFPH and V(V) ions respectively, were statistically valid. This because of the ratio (MSreg/MSerror) for 1 and 7 dof, and 1 and 8 dof, larger than critical value $\left(\mathrm{F}_{1,7}=5.59\right.$ and $\mathrm{F}_{1,8}=5.32$ at $\left.\alpha=0.05\right)$, indicating that the predication based on the regression line is satisfactory as listed in Table 3.

Table 1. The statistical data and analytical figures of merits for TFPH using $V(V)$ ions by CPE-Spectrophotometry.

\begin{tabular}{ll}
\hline Parameter & TFPH \\
\hline Colour of complex & Orange-purple \\
$\lambda_{\text {max }}(\mathrm{nm})$ & 476 \\
Regression equation & $\mathrm{y}=0.0111 \mathrm{x}-00068$ \\
Correlation coefficient(r) & 0.9999 \\
Coefficient of determination $\left(\mathrm{R}^{2}\right)$ & $99.98 \%$ \\
C.L. for the slope $\left(\mathrm{b} \pm \mathrm{ts}_{\mathrm{b}}\right)$ at $95 \%$ & $0.0111 \pm 0.00012$ \\
C.L. for the intercept $\left(\mathrm{a} \pm \mathrm{ts}_{\mathrm{a}}\right)$ at $95 \%$ & $-0.00068 \pm 0.0056$ \\
Concentration range $\left(\mu \mathrm{g} \mathrm{m} \mathrm{m}^{-1}\right)$ & $2-80$ \\
Limit of Detection $\left(\mu \mathrm{g} \mathrm{mL} \mathrm{mL}^{-1}\right)$ & 1.21 \\
Limit of Quantitation $\left(\mu \mathrm{g} \mathrm{mL} \mathrm{m}^{-1}\right)$ & 4.04 \\
Sandell's sensitivity $\left(\mathrm{mg} \mathrm{cm}^{-2} / 0.001 \mathrm{~A} . \mathrm{U}\right)$ & 0.090 \\
Molar absorptivity $\left(\mathrm{L} . \mathrm{mol}^{-1} . \mathrm{cm}^{-1}\right)$ & $6.4 \times 10^{3}$ \\
Compsition of complex $(\mathrm{V}-\mathrm{TFPH})^{*}$ & $1: 1$ \\
RSD\% (n=3) & 1.18 at $15 \mu \mathrm{g} \mathrm{mL}$ \\
RSD\% (n=3) & 0.37 at $60 \mu \mathrm{g} \mathrm{mL} \mathrm{m}^{-1}$ \\
Preconcentration factor & 50 \\
Enrichment factor & 19 \\
Distribution ratio(D) & 18 \\
Extraction efficiency $(\% \mathrm{E})$ & 94.73 \\
\hline
\end{tabular}

*Job's and mole ratio methods 
Table 2. The statistical data and analytical figures of merits for $V(V)$ using TFPH by CPE- Spectrophotometry.

\begin{tabular}{ll}
\hline Parameter & $\mathbf{V}(\mathbf{V})$ ion \\
\hline Colour of complex & Orange-purple \\
$\lambda_{\max }(\mathrm{nm})$ & 476 \\
Regression equation & $\mathrm{y}=0.0308 \mathrm{x}+0.0058$ \\
Correlation coefficient $(\mathrm{r})$ & 0.9995 \\
Coefficient of determination $\left(\mathrm{R}^{2}\right)$ & $99.90 \%$ \\
C.L. for the slope $\left(\mathrm{b} \pm \mathrm{ts}_{\mathrm{b}}\right)$ at $95 \%$ & $0.0308 \pm 0.0032$ \\
C.L. for the intercept $\left(\mathrm{a} \pm \mathrm{ts}_{\mathrm{a}}\right)$ at $95 \%$ & $0.0058 \pm 0.0018$ \\
Concentration range $\left(\mu \mathrm{g} \mathrm{mL}^{-1}\right)$ & $0.5-10$ \\
Limit of Detection $\left(\mu \mathrm{gL}^{-1}\right)$ & 0.113 \\
Limit of Quantitation $\left(\mu \mathrm{g} \mathrm{mL}^{-1}\right)$ & 0.380 \\
Sandell's sensitivity $\left(\mathrm{mg} \mathrm{cm}^{-2} / 0.001 \mathrm{~A} . \mathrm{U}\right)$ & 0.032 \\
Molar absorptivity $\left(\mathrm{L} \cdot \mathrm{mol}^{-1} . \mathrm{cm}^{-1}\right)$ & $1.78 \times 10^{4}$ \\
Compsition of complex $\left(\mathrm{V}-\mathrm{TFPH}^{*}\right.$ & $1: 1$ \\
RSD $\%(\mathrm{n}=3)$ at $2 \mu \mathrm{g} \mathrm{mL} \mathrm{m}^{-1}$ & 2.14 \\
RSD $\%(\mathrm{n}=3)$ at $10 \mu \mathrm{g} \mathrm{mL}{ }^{-1}$ & 0.44 \\
Preconcentration factor & 50 \\
\hline
\end{tabular}

Concerning the limit of detection for the drug TFPH, our finding was in harmony with that obtained by Karimi et al [20] using indirect spectrophotometric method and principal component regression (PCR), partial least squares (PLS) and orthogonal signal correction (OSC)-PLS multivariate calibration methods and was 8 -fold better better than that obtained by Navyasri et al [12] and 2-fold better than that obtained by Pattanayak and Ash Rani [11] whom using RP-HPLC method. However, it was worse than that obtained by Sharma etal [6] Patel and Patel [7], Parvataneni and Nagarjuna [13] using the developed RP-HPLC, and Waleed [4] using indirect flame AAS. Regarding the detection limit of vanadium, it observed that it was not good as with those obtained by Liu and Jiang [32], Okamoto et al [35] and Khammas et al [37] whom used more sophisticated instrumentation such as ICP-MS, ETA-ICP-OES and CPE-spectrophotometry using newly prepared organic reagent, respectively. However, by considering the detection limit of $\mathrm{V}(\mathrm{V})$ ions is $113 \mu \mathrm{g} / \mathrm{L}$ in aqueous solution and $5 \mathrm{~g}$ of sample in $5 \mathrm{~mL}$, the method detection limit is $0.113 \mu \mathrm{g} / \mathrm{g}$. This finding has encouraged the application of the proposed method successfully in the estimation of $\mathrm{V}(\mathrm{V})$ ion species in water, black pepper and rice samples to test its applicability and reliability.

Table 3. Analysis of Variance of regression line for TFPH and V(V) ion.

\begin{tabular}{lllllc}
\hline \multirow{2}{*}{ Analyte } & Source & dof & SS & MS & F \\
\cline { 2 - 5 } & & & & & \\
\hline \multirow{3}{*}{ TFPH } & Regression & 1 & 0.043858 & 0.043858 & 28929.4 \\
& Residual Error & 7 & $1.06 \mathrm{E}-05$ & $1.52 \mathrm{E}-06$ & \\
& Total & 8 & 0.043868 & & \\
& Regression & 1 & 0.075654 & 0.075654 & 6654.072 \\
$\mathrm{~V}(\mathrm{~V})$ & Residual Error & 6 & $6.82 \mathrm{E}-05$ & $1.14 \mathrm{E}-05$ & \\
& Total & 7 & 0.075722 & & \\
\hline
\end{tabular}

Dof=degrees of freedom, SS: sum of squares, MS: mean of squares, F (Fisher F-test)

\subsection{Accuracy and Precision}

Since the certificate reference materials (CRM's) that define exactly the true value are not available for the determination of TFPH and/ or V (V) ions, the trueness of the developed method was evaluated with accuracy test in the term of recovery percentage by spiking three blank water (tap and river) samples collected from the University Campus with standard solutions of TFPH and/or V (V) ions and subjected to the general CPE procedure according to each target analyte. The results are tabulated in Tables 4 and 5. The data revealed that the accuracies of the proposed method were within acceptable level for the determination of both TFPH drug using $\mathrm{V}(\mathrm{V})$ ions, and $\mathrm{V}(\mathrm{V})$ ions using TFPH as chelating agent, indicative the established method is unbiased. This can confirm that the proposed method is relatively free from matrix interferences. In the meantime, an intra-precision (i.e. repeatability) of the proposed method was also carried out with the same spiked samples for three replicate measurements and the RSD\% found to be in the range of $0.84-3.40 \%$ (Table 3) for TFPH using $\mathrm{V}(\mathrm{V})$ ions and $0.45-1.49 \%$ (Table 4 ) for V (V) ion determination using TFPH, indicative the proposed method is highly free from random errors.

Table 4. The accuracy and precision of the proposed method for the determination of TFPH using V(V) in tap and river water.

\begin{tabular}{|c|c|c|c|c|c|c|}
\hline sample & $\begin{array}{l}\text { Amount TFPH taken } \\
\left(\mu \mathrm{g} \mathrm{mL}^{-1}\right)\end{array}$ & $\begin{array}{l}\text { Amount TFPH found } \\
\left(\mu \mathrm{g} \mathrm{mL}^{-1}\right)\end{array}$ & Recovery (\%) & $\mathbf{E}_{\text {rel }}(\%)$ & Mean Rec. \pm ts $/ \sqrt{ }$ n (\%) & $\operatorname{RSD}(\%)(n=3)$ \\
\hline \multirow{3}{*}{ Tap water } & 10 & 10.2 & 102.0 & 2.00 & \multirow{3}{*}{$99 . .93 \pm 2.88$} & 2.70 \\
\hline & 30 & 29.6 & 98.0 & -1.30 & & 1.50 \\
\hline & 50 & 49.9 & 99.8 & -0.20 & & 0.90 \\
\hline \multirow{3}{*}{ River water } & 10 & 09.94 & 99.4 & -0.60 & \multirow{3}{*}{$99.33 \pm 3.45$} & 3.40 \\
\hline & 20 & 19.38 & 96.9 & -3.10 & & 3.19 \\
\hline & 40 & 40.70 & 101.7 & 1.75 & & 0.84 \\
\hline
\end{tabular}



Vanadium (V) Ions in Real Matrices by Visible Spectrophotometry After Cloud Point Extraction

Table 5. The accuracy and precision of the proposed method for the determination of V(V) using TFPH in tap and river water.

\begin{tabular}{|c|c|c|c|c|c|c|}
\hline sample & $\begin{array}{l}\text { Amount of } V(V) \text { taken } \\
\left(\mu \mathrm{gL}^{-1}\right)\end{array}$ & $\begin{array}{l}\text { Amount of } \mathrm{V}(\mathrm{V}) \text { found } \\
\left(\mu \mathrm{g} \mathrm{mL} \mathrm{L}^{-1}\right)\end{array}$ & Recovery (\%) & $E_{\text {rel }}(\%)$ & Mean Rec. \pm ts $/ \sqrt{ } \mathbf{n}(\%)$ & $\operatorname{RSD}(\%)(n=3)$ \\
\hline \multirow{3}{*}{ Tap water } & 2 & 2.02 & 101.0 & 1.00 & \multirow{3}{*}{$99 . .43 \pm 1.40$} & 1.49 \\
\hline & 4 & 3.96 & 99.0 & -1.00 & & 0.83 \\
\hline & 6 & 5.90 & 98.3 & -1.60 & & 0.45 \\
\hline
\end{tabular}

\subsection{Applications}

Of the results obtained in the above-mentioned, it was shown that the established method gave satisfactory figures of merit for the standard aqueous solutions. Also, it has achieved promising results in terms of accuracy and precision in real samples for both target analytes which means that this method is free from crucial interferences, and encourage to test its applicability to a variety of samples below.

\subsubsection{Determination of TFPH Using V(V) as Mediating Metal Ion}

The proposed CPE- Spectrophotometry was applied for the determination of TFPH as an active ingredient of Stelazine tablet containing $5 \mathrm{mg}$ TFPH per unit (Cairo Pharmaceuticals and Chemical Industries/Egypt). The results summarized in Table 6 have revealed that the calculated t-value of 2.23 for TFPH determination using $\mathrm{V}(\mathrm{V})$ as mediating metal ion was less than the t-critical (4.303) at $\alpha=0.05$ level and (n-1) degrees of freedom, indicating the acceptance of null hypothesis (Ho) and concluding there is no evidence for systematic and random errors at the $95 \%$ confidence level, thus manufacturer's claim can be acceptable. This finding is a good agreement with results of our previously reported method based on indirect FAAS [4].

The applicability of the developed method was examined by spiking 20,30 and $40 \mu \mathrm{g} \mathrm{mL}^{-1}$ of TFPH standard solutions to serum sample and the preconcentrated according to general CPE procedure, then determined by Vis-spectrophotometry. The average recovery obtained within $98.94 \pm 5.42 \%$ as illustrated in Table 7 , seems to suggest again that the developed method is feasible and reliable, at least, for the sample analysed for trace level of TFPH drug.

Table 6. Determination of TFPH in pharmaceutical formulation by the proposed method and statistical comparison with quoted values.

\begin{tabular}{|c|c|c|c|c|c|}
\hline $\begin{array}{l}\text { Commercial name*, and } \\
\text { content }\end{array}$ & $\begin{array}{l}\text { Practical content (proposed } * * \\
\text { method) }(\mathrm{mg} / \text { tablet) }\end{array}$ & $\begin{array}{l}\text { Average TFPH (mg /tablet) } \\
(\bar{x} \pm \text { ts } / \sqrt{ } \text { n) at } \alpha=0.05\end{array}$ & $\begin{array}{l}t=(\bar{x}-\mu) \sqrt{ } n / s \text { Proposed method* } \\
\text { versus quoted value at } \alpha=0.05\end{array}$ & $\mathbf{E}_{\text {rel }}(\%)$ & $\begin{array}{l}\text { RSD (\%) } \\
\mathrm{n}=3\end{array}$ \\
\hline Stelazine & 4.80 & \multirow{3}{*}{$4.89 \pm 0.21$} & $\mathrm{t}_{\mathrm{cal}}=2.23$ & \multirow{3}{*}{-2.2} & \multirow{3}{*}{4.79} \\
\hline Tablet, & 4.90 & & $2.23<4.303$ & & \\
\hline Quoted value (5mg /tablet) & 4.97 & & & & \\
\hline
\end{tabular}

*Cairo Pharmaceuticals and Chemical Industries/Egypt

**Mean of three determinations

Table 7. Determination of TFPH using V (V) in blood serum by the prposed method.

\begin{tabular}{|c|c|c|c|c|c|}
\hline $\begin{array}{l}\text { Amount of TFPH taken } \\
\left(\mu \mathrm{g} \mathrm{mL}^{-1}\right)\end{array}$ & $\begin{array}{l}\text { Amount of TFPH found } \\
\left(\mu \mathrm{g} \mathrm{mL}^{-1}\right)\end{array}$ & Recovery (\%) & $\mathbf{E}_{\text {rel }}(\%)$ & Mean Rec. \pm ts $/ \sqrt{ }$ n $(\%)$ & RSD \% $(n=3)$ \\
\hline 20 & 19.38 & 96.90 & -3.10 & \multirow[t]{3}{*}{$98 . .94 \pm 5.42$} & 1.58 \\
\hline 30 & 29.60 & 98.66 & -1.33 & & 0.93 \\
\hline 40 & 40.50 & 101.25 & 1.25 & & 0.48 \\
\hline
\end{tabular}

Table 8. Determination of vanadium ions in black pepper samples with statistical paired t-test at 95\% confidence level.

\begin{tabular}{|c|c|c|c|}
\hline Sample & Proposed method $\bar{x} \pm t s / \sqrt{ } n\left(\mu g^{-1}\right)$ & ETAAS method $\overline{x^{ \pm}} \mathrm{t} s / \sqrt{ } n\left(\mu g^{-1}\right)$ & Paired t-test at $95 \%$ C.I $|t|=x_{d} \sqrt{ } / s_{d}$ \\
\hline Malwiya (Iraqi brand) & $0.528 \pm 0.039$ & $0.490 \pm 0.133$ & \multirow{3}{*}{$\begin{array}{l}\overline{\mathrm{X}_{d}}=-0.059333 \\
\mathrm{~S}_{d}=0.085617 \\
\mathrm{t}_{\text {cal }}(\mathrm{n}=3)=1.20 \\
\mathrm{t}_{\text {crit }} \text { at } 95 \% \text { CI,dof, } 2=4.303\end{array}$} \\
\hline Amercana (USA) & $0.696 \pm 0.071$ & $0.789 \pm 0.172$ & \\
\hline Meshwar (Syrian brand) & $0.958 \pm 0.105$ & $1.081 \pm 0.212$ & \\
\hline
\end{tabular}

\subsubsection{Determination of V(V) Ion Using TFPH Chelating Agent}

The established method revealed that the detection limit of the method was of $0.113 \mu \mathrm{g} / \mathrm{g}$, by considering $113 \mu \mathrm{g} / \mathrm{L}$ and 5 $\mathrm{g}$ of food sample in $5 \mathrm{~mL}$ solution. This finding encouraged to analyze vanadium ions in black pepper collected from Iraqi local markets. Table 8 summarized the content of vanadium ions measured in triplicate by the developed method and ETASS method.
The results in Table 8 showed that the calculated $t$-value (1.20) for vanadium determination using TFPH drug as the chelating agent are less than t-tabulated (4.303) at 95\% confidence interval and (n-1) degrees of freedom, indicative the acceptance of null hypothesis $\left(\mathrm{H}_{\mathrm{o}}\right)$, and concluding no significant difference between the proposed method and ETAAS. So, our findings were in harmony with that reported by López-García et al [42] who claimed that the black pepper contains vanadium between 431 and $987 \mu \mathrm{g} \mathrm{kg}^{-1}$. 


\section{Conclusions}

This study shows the competence of the mutual detection of both target analytes in the same reaction system by coupling $\mathrm{CPE}$ and Vis-spectrophotometry. The inherent benefits of the proposed method are time-saving, lessening in reagents used and analyst effort. This works also reveals the possibility of the determination the drug TPH in variety of biological and environmental matrices other than in drug formulations due to its sensitivity and reliability. In addition, TFPH can be considered a good analytical reagent that produces a sensitive colour with vanadium (V), giving a complex absorbed at $\lambda_{\max }$ of $476 \mathrm{~nm}$ with $1: 1$ stoichiometry at $\mathrm{pH}=1.5$, and reasonable molar absorptivity that permits the detection of vanadium ions from $0.5-10 \mu \mathrm{g} \mathrm{mL}$.

\section{References}

[1] Z. A-A. Khammas, and N. S. Mundir, "Cloud point extraction spectrophotometric method for mutual determination of Norfloxacin and Iron (III) in human serum and drug formulations," Chem. Sci. Transactions, 4(2), pp. 483-497, 2015.

[2] J. Karpinska, B. Starczweska, and H. Puzanowska-Tarasiewicz" Analytical properties of and 10-disubstituted phenothiazine derivatives," Anal. Sci., 129, pp. 161-170, 1996.

[3] C. A. Howard, "Pharmaceutical dosage forms and drug delivery systems," 5th edn, pp. 51 and 196. Lee and Fibiger publisher, London (1990).

[4] A. Q. Waleed Z. A-A. Khammas, A. S. Al-Ayash, and F. Jasim, "An indirect atomic absorption spectrophotometric determination of trifluoperazine hydrochloride in pharmaceuticals,” Arab J. Sci. Eng., 36, pp.553-563, 2011.

[5] A. K. Hassan, S. T. Ameen, B. Saad, and S. M. Al-Aragi," Potentiometric sensors for the determination of trifluoperazine hydrochloride in pharmaceutical preparations," Anal. Sci., 25(11), pp.1295-1299, 2009.

[6] D. Sharma, A. Shrivastava1, D. Duggal, and A. Patel," Stability Indicating RP-HPLC method for the estimation of trifluoperazine hydrochloride as API and estimation in tablet dosage forms", International Journal of Pharmaceutical Quality Assurance," 2(2), pp. 38-41, 2010.

[7] S. K. Patel, and N. J. Patel," Simultaneous RP-HPLC estimation of trifluoperazine hydrochloride and chlordiazepoxide in tablet dosage form," Indian J Pharm Sci., 71(5), pp. 545-547, 2009.

[8] Manoj, C. Imran, S., Sarika, D. and Avinash, K.," RP-HPLC method for simultaneous estimation of benzhexol hydrochloride and trifluoperazine hydrochloride in their combined dosage form,” J. Pharm. Res., 3(7), pp. 1616, 2010.

[9] P. Shetti and A. Venkatachalam A, "Stability indicating HPLC method for simultaneous quantification of trihexyphenidyl hydrochloride, trifluoperazine hydrochloride and chlorpromazine. E-J Chem., 7(1), pp. S299-S313, 2010.

[10] M. Jameel, H. A. Taufeeq and A. K. Tarik, "Simultaneous determination of fluphenazine, trifluoperazine, and prochloroperazine in pharmaceutical preparations by HPLC method," J. Int. Environ. Appl. and Sci., 7 (3), pp. 503- 510, 2012.
[11] S. Pattanayak, and Y. Ash Rani, "A novel RP-HPLC method development and validation for simultaneous estimation of trifluoperazine and isopropamide in tablet dosage form," International Journal of Pharmaceutical Sciences and Drug Research, 7(1) pp. 105-109, 2015.

[12] D. Navya sri, T. Ramamohan Reddy, A. Ajitha, and V. Uma Maheshwara Rao," Method development and validation for the simultaneous estimation of trifluoperazine and isopropamide in tablet dosage form by RP-HPLC," International Journal of Pharmaceutical Research \& Analysis, 4 (8), pp. 449-455, 2014.

[13] S. V. Parvataneni, and P. J. Nagarjuna," Development and validation for the simultaneous determination of trifluoperazine hydrochloride and trihexyphebidyl hydrochgloride in a solid oral dosage form by RP-HPLC", World Journal of Pharmacy and pharmaceutical sciences, 3(10), pp. 1021-1031, 2014.

[14] A. M. Attaran, N. Mohammadi, M. Javanbakht and B. Akbari-Adergani," Molecularly imprinted solid-phase extraction for selective trace analysis of trifluoperazine", J.Chromatogr. Sci., 52(7), pp. 730-738, 2013.

[15] P. Shetti, and A. Venkatachalam," LC-MS/MS determination of trihexaphenydyl $\mathrm{HCl}$, trifluoperazine $\mathrm{HCl}$ and chlorpromazine $\mathrm{HCl}$ from blood plasma," J. Pharm. Biomed. Sci., 9(7), pp. 1-10, 2011.

[16] M. C. Sharma, and C. Shama," Developmentt and validation of densitometry estimation of trifluoperazine hydrochloride in dosage form", American-Eurasian Journal of Toxicological Sciences, 3(2), pp. 101-104, 2011.

[17] C. M. Bhaskar Reddy, G. V. Subba Reddy, and N. Ananda Kumar Reddy," Development and validation of U V spectrophotometric method for determination of trifluoperazine hydrochloride in bulk and pharmaceutical dosage form," International Journal of Scientific and Research Publications, 2( 8), pp. 1-5, 2012.

[18] M. E. M. Hassouna, A. M. Adawi, and E. A. Ali,” Extractive spectrophotometric determination of chlorpromazine and trifluoperazine hydrochloride in pharmaceutical preparations," Egyptian Journal of Forensic Sciences, 2(2), pp. 62-68, 2012.

[19] R. B. Saudagar," Spectrophotometric determination of chlordiazepoxide and trifluoperazine hydrochloride from combined dosage form," Indian J Pharm. sci. 69(2), pp. 149-152, 2007.

[20] M. A. Karimi, M. M. Ardakani, R. Behjatmanesh-Ardakani, M. R. H. Nezhad, and H. Amiryan," Individual and simultaneous determinations of phenothiazine drugs using PCR, PLS and (OSC)-PLS multivariate calibration methods," J. Serb. Chem. Soc. 73 (2), pp. 233-247, 2008.

[21] H. D. Revanasiddappa, and T. N. Kiran Kumar," Rapid spectrophotometric determination of chromium with trifluoperazine hydrochloride", Chem. Anal. (Warsaw), 47, pp. 311-313, 2002.

[22] R. H. Devanasiddappa, and T. N. Kiran Kumar,” A simple and rapid spectrophotometric determination of thallium (III) with trifluoperazine hydrochloride", Anal. Sci., 18 (10), pp. 1131-11355, 2002.

[23] H. Puzanowska-Tarasiewicz, J. Karpínska, and L. Kúzmicka,” Analytical applications of reactions of iron (III) and hexacyanoferrate (III) with 2, 10-disubstituted phenothiazines," Int. J. Anal. Chem., 2009, pp.1-8, 2009. 
[24] M. Tarasiewicz, H. Puzanowska-Tarasiewicz, W. Misiuk, A. Kojło, A. Grudniewska, andB. Starczewska, "Analytical applications of the reactions of 2-and 10-disubstituted phenothiazines with some metal ions," Chem. Anal., 44, pp.137-155, 1999.

[25] R. Liasko, T. A. Kabanos, S. Karkabounas, M. Malamas, A. J. Tasiopoulas, D. Stefanou, P. Collery, and A. Evangelou, "Beneficial effects of a vanadium complex with cysteine, administered at low doses on benzo (alpha) pyrene-induced leiomyosarcomas in Wistar rats," Anticancer Res.,18, pp.36093613, 1998.

[26] B. Venugopal, and T. D. Luckey," Metal Toxicity in mammals," Plenum Press, New York, 220.1979.

[27] R. J. Cassella, E. P. Oliveira, and O. I. B. Magalhaes,” Direct determination of vanadium in high saline produced waters from offshore petroleum exploration by electrothermal atomic absorption spectrometry," Talanta, 69, pp. 48- 54, 2006.

[28] W. Wu, S.-H. Qian, M. Xiao, G.-Q. Huang, and H. Chen, H., "Preconcentration of vanadium (V) on cross linked chitosan and determination by graphite furnace atomic absorption spectrometry," Wuhan University Journal of Natural Science, 7, pp. 222-226, 2002.

[29] Y. Nir-El, and N. Lavi," Determination of vanadium in the presence of aluminium by neutron activation analysis, "Journal of Radioanalytical Chemistry, 55(1), pp. 125-130, 1980.

[30] R. Cornelis, J. Versieck, L. Mees, J. Hoste, and F. Barbier," Determination of vanadium in human serum by neutron activation analysis", Journal of Radioanalytical Chemistry, 55(1), pp. 35-43, 1980.

[31] A. A. Al-gadi, and H. M. Al-swaidan "Determination of vanadium in Saudi Arabian crude oil by inductively coupled plasma - mass spectrometry (ICP/MS)," Analytical Letters, 23(9), pp. 1757-1764, 1990.

[32] H. Liu, and S.-J. Jiang," Determination of vanadium in water samples by reaction cell inductively coupled plasma quadrupole mass spectrometry," J. Anal. Atom. Spectrom, 17(5), pp. 556-559, 2002.

[33] V. Dupont, Y. Auger, C. Jeandel, and M. Wartel,'Determination of vanadium in seawater by inductively coupled plasma atomic emission spectrometry using chelating resin column preconcentration," Anal. Chem., 63 (5), pp.520-522, 1991.
[34] E. M. Sedykh, L. N. Bannykh, G. S. Korobeinik, and N. P. Starshinova," Determination of nickel and vanadium in crude oils by electrothermal atomic absorption spectrometry and inductively coupled plasma atomic emission spectroscopy after mineralization in an autoclave," Inorganic Materials, 47(14), pp. 1539-1543, 2011.

[35] Y. Okamoto, H. Murata, M. Yamamoto, and T. Kumamaru," Determination of vanadium and titanium in steel by inductively coupled plasma atomic emission spectrometry with modified use of a tungsten boat furnace atomizer for atomic absorption spectrometry," Anal. Chim. Acta, 239, pp. 139-143, 1990.

[36] I. Aydin, F. Aydin, E. Kilinc, and C. Hamamci," Detemination of vanadium in Turkish asphaltites," Oil Shale, 27(4), pp. $331-338,2010$

[37] S. Girousi, I. Gherghi, A. Voulgaropoulos and I. Stratis, "Voltammetric determination of vanadium by using 1 , 10-phenanthroline as a complexing agent," International Journal of Environmental Analytical Chemistry, 75, pp.83-91 1999.

[38] Z. A. A. Khammas, Z. T. Ibrahim1 and K. J. Al-adilee," Two-steps cloud point extraction spectrophotomtric method for separation preconcentration and determination of $\mathrm{V}$ (IV) and $\mathrm{V}$ (V) ions in real samples using laboratory-made organic reagents," International Research Journal of Pure and Applied Chemistry, 8(1), pp. 33-48, 2015.

[39] J. L. Manzoori, and G. Karim-Nezhad," Development of a cloud point extraction and preconcentration method for $\mathrm{Cd}$ and $\mathrm{Ni}$ prior to flame atomic absorption spectrometric determination," Anal. Chim. Acta, 521, pp. 173-177, 2004.

[40] S. Brewer, "Solving problems in analytical chemistry" John Wiley and Sons, USA, pp.289-299, 1980.

[41] W. F. El-Hawary, and F. K. Al-Gethami," Mutual spectrophotometric determination of moxifloxacin drug and iron(III) by formation of a complex compound "Eur, Chem. Bull., 2,pp. 22-27, 2013.

[42] López-García, I., Vinas, P., Romero-Romero, R. and Manuel Hernández-Córdoba, M.," Ion-exchange preconcentration and determination of vanadium in milk samples by electrothermal atomic absorption spectrometry", Talanta, 78, pp. 1458-1463, 2009. 